\title{
20. MAGNETIC PROPERTIES OF IGNEOUS SAMPLES, LEG 37
}

\author{
M.E. Evans, Institute of Earth and Planetary Physics, University of Alberta, Edmonton, Alberta, Canada \\ and
}

M.L. Wayman, Department of Mineral Engineering, University of Alberta, Edmonton, Alberta, Canada

\section{INTRODUCTION}

The general complexity of the NRM data and the preponderance of shallow inclinations observed by the shipboard party in Leg 37 basalts are very puzzling. We have investigated two possible causes of the observed behavior, namely, viscous remanent magnetization and magnetic anisotropy.

To further aid the understanding of the nature of the remanence carried by these basalts, thermal demagnetization and microscope investigation have been carried out.

\section{VISCOUS REMANENT MAGNETIZATION}

The acquisition of VRM by six igneous specimens has been determined by monitoring the magnetization acquired in a 9.6-oe field for periods up to about $100 \mathrm{hr}$. Prior to the experiment, the specimens were demagnetized in 1800-oe peak alternating field to remove the bulk of the NRM. Five of the six specimens yielded very clear relationships between VRM and the logarithm of time (Figure 1), the sixth showing a marked increase in the rate of VRM build-up after about 20 hr. Values of the magnetic viscosity coefficient (S), assuming it depends linearly on ambient field (Shimuzu, 1960), are given in Table 1. The salient point is that the viscosity coefficients are sufficiently small that VRM acquired throughout the Brunhes Normal Epoch in the present ambient field at $37^{\circ} \mathrm{N}(0.45$ oe $)$ will be very small $(<6 \%)$ compared to the observed NRM. Sample 332B-11-1, 115-118 cm exhibits peculiar behavior which is not at present understood. However, it is noteworthy that this specimen represents what is probably a doleritic intrusion, whereas the other specimens are basalts which are more representative of Layer 2 as a whole. If the apparent increase in $\mathrm{S}$ after about $20 \mathrm{hr}$ is simply used to extrapolate a Brunhes Epoch VRM, one obtains a remanence whose magnitude is $30 \%$ of the NRM value of this specimen.

It would appear that viscous remanence is not a major source of magnetic overprinting in these rocks.

\section{MAGNETIC ANISOTROPY}

Magnetic anisotropy has been tested in two ways. The anisotropy of magnetic susceptibility of 10 basalt specimens was determined by means of a spinner magnetometer described by Boetzkes and Gough (1976). The degree of anisotropy is generally low, with a maximum anisotropy of $10.6 \%$ (see Table 2 for results and definition of \% age anisotropy). In the worst possible case this maximum observed anisotropy would serve to deflect TRM by only $3^{\circ}$ (McElhinny, 1973).
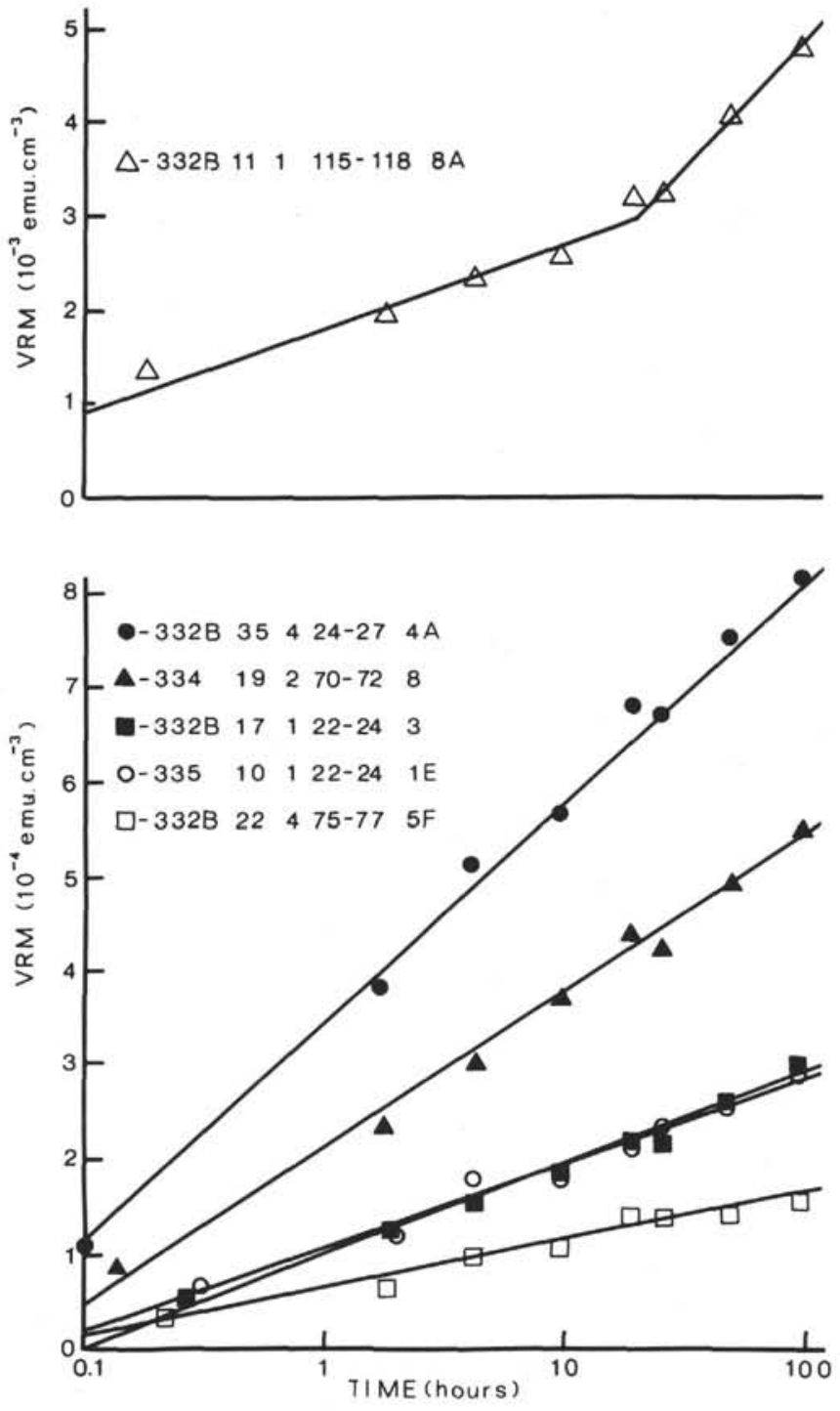

Figure 1. Acquisition of viscous remanent magnetization in six igneous specimens (see, also, Table 1).

This demonstrates that the unexpectedly shallow NRM directions common in Leg 37 basalts cannot be attributed to anisotropy of magnetic susceptibility.

A second experiment to test the directional fidelity of this material involved acquisition of low field (1.2 oe) anhysteretic remanence (ARM). The same 10 specimens were used, after preliminary demagnetization in the 1800-oe peak alternating field, and the results (Table 2) indicate that the induced remanence parallels the ambient field within experimental error. 
TABLE 1

Viscous Remanent Magnetization in DSDP Leg 37 Igneous Samples

\begin{tabular}{|c|c|c|c|c|c|}
\hline $\begin{array}{c}\text { Sample } \\
\text { (Interval in } \mathrm{cm} \text { ) }\end{array}$ & $\mathrm{r}^{\mathrm{a}}$ & $s^{b}$ & $V_{R M}{ }^{c}$ & $\frac{\text { VRM }}{\text { NRM }}(\%)$ & Lithology ${ }^{d}$ \\
\hline \multicolumn{6}{|l|}{ Hole 332B } \\
\hline $\begin{array}{l}11-1,115-118 \\
17-1,22-24 \\
22-4,75-77 \\
35-4,24-27\end{array}$ & $\begin{array}{l}(0.998)^{\mathrm{e}} \\
0.990 \\
0.993 \\
0.997\end{array}$ & $\begin{array}{c}(124) \\
4.5 \\
2.2 \\
11\end{array}$ & $\begin{array}{r}(1200) \\
49 \\
25 \\
125\end{array}$ & $\begin{array}{l}(30) \\
0.45 \\
0.66 \\
5.7\end{array}$ & $\begin{array}{l}\text { Microdolerite } \\
\text { Basalt } \\
\text { Basalt } \\
\text { Basalt }\end{array}$ \\
\hline \multicolumn{6}{|l|}{ Site 334} \\
\hline $19-2,70-72$ & 0.996 & 7.6 & 85 & 3.1 & Basalt \\
\hline \multicolumn{6}{|l|}{ Site 335} \\
\hline $10-1,22-24$ & 0.994 & 4.1 & 45 & 1.2 & Basalt \\
\hline
\end{tabular}

${ }^{a}$ Correlation coefficient obtained from least-squares regression line between magnetization and $\log _{10}(\mathrm{hr})$.

${ }^{b}$ Magnetic viscosity coefficient $\left(10^{-6} \mathrm{emu} \mathrm{cm}^{-3}\right)$. Values quoted are those appropriate for an ambient field of 0.45 oe (field at $37^{\circ} \mathrm{N}$ ).

${ }^{c}$ VRM $\left(10^{-6}\right.$ emu $\left.\mathrm{cm}^{-3}\right)$ acquired in 0.45 oe throughout the Brunhes Normal Epoch $(700,000 \mathrm{yr})$, using least-squares line.

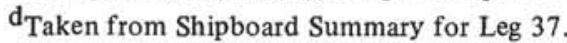

${ }^{e_{B}}$ Bracketed results refer to steeper part VRM build-up curve for Sample $11-1,115-118 \mathrm{~cm}$ (See Figure 1).

TABLE 2

Magnetic Anisotropy of DSDP Leg 37 Basalt Samples

\begin{tabular}{|c|c|c|}
\hline $\begin{array}{c}\text { Sample } \\
\text { (Interval in } \mathrm{cm} \text { ) }\end{array}$ & $\begin{array}{c}\text { Anisotropy }{ }^{\mathrm{a}} \\
(\%)\end{array}$ & $\begin{array}{c}\text { Angular } \\
\text { Deflection }{ }^{\circ}\left({ }^{\circ}\right)\end{array}$ \\
\hline $332 \mathrm{~B}-1-5,120-123$ & 0.6 & 1 \\
\hline 332B- $9-3,80-82$ & 6 & 2 \\
\hline 332B-19-1, 104-107 & 1.8 & 3 \\
\hline $332 \mathrm{~B}-22-4,11-13$ & 3.4 & 2 \\
\hline $332 \mathrm{~B}-25-2,91-93$ & 4.1 & 3 \\
\hline 332B-36-6, 44-46 & 10.6 & 4 \\
\hline $332 \mathrm{~B}-47-2,145-147$ & 1.4 & 2 \\
\hline $334-18-1,84-87$ & 2.8 & 3 \\
\hline $335-8-3,79-81$ & 3.2 & 5 \\
\hline $335-14-4,63-65$ & 3.4 & 2 \\
\hline Mean & 3.8 & 3 \\
\hline \multicolumn{3}{|c|}{ 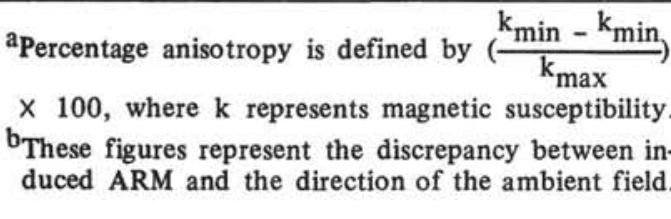 } \\
\hline
\end{tabular}

\section{THERMAL DEMAGNETIZATION}

Sixteen specimens were subjected to stepwise thermal demagnetization in $50^{\circ} \mathrm{C}$ steps from $50^{\circ}$ to $550^{\circ}$ and then at $575^{\circ}$ and $600^{\circ} \mathrm{C}$. All heatings were carried out in air. Eleven specimens show no significant directional change between room temperature and $575^{\circ} \mathrm{C}$, and a further two are stable as far as $550^{\circ} \mathrm{C}$. Beyond these temperatures, directions are variable. Of the remaining three specimens, one (332B-11-1, 115-118 $\mathrm{cm}$ ) moves along a great circle about $35^{\circ}$ before coming to a well-determined end-point between $300^{\circ}$ and $550^{\circ} \mathrm{C}$. A second specimen (332B-47-3, 21-24 cm) moves similarly but is not stable beyond $350^{\circ} \mathrm{C}$. The final specimen $(334-24-3,55-58 \mathrm{~cm})$ moves $35^{\circ}$ along a great circle path, but exhibits no end-point and becomes random beyond $200^{\circ} \mathrm{C}$. Results are briefly summarized in Table 3 . Since the magnetic carrier in submarine basalts is generally a titanomagnetite rather than pure $\mathrm{Fe}_{3} \mathrm{O}_{4}$, the observed high-temperature stability is puzzling. However, Irving et al. (1970) report very similar results from material dredged at $45^{\circ} \mathrm{N}$ on the Mid-Atlantic Ridge, and in his review, Irving (1970)

TABLE 3

Thermal Demagnetization in DSDP Leg 37 Igneous Samples

\begin{tabular}{lcc}
\hline $\begin{array}{c}\text { Sample } \\
\text { (Interval in cm) }\end{array}$ & $\mathrm{T}_{1}\left({ }^{\circ} \mathrm{C}\right)^{\mathrm{a}}$ & $\mathrm{T}_{2}\left({ }^{\circ} \mathrm{C}\right)^{\mathrm{b}}$ \\
\hline $332 \mathrm{~B}-1-5,43-46$ & 575 & 460 \\
$332 \mathrm{~B}-3-4,135$ & 575 & 520 \\
$332 \mathrm{~B}-4-1,100$ & 575 & 460 \\
$332 \mathrm{~B}-11-1,115-118$ & 550 & 200 \\
$332 \mathrm{~B}-17-1,22-24$ & 575 & 480 \\
$332 \mathrm{~B}-22-4,75-77$ & 575 & 450 \\
$332 \mathrm{~B}-27-2,101-103$ & 550 & 460 \\
$332 \mathrm{~B}-35-4,24-27$ & 575 & 450 \\
$332 \mathrm{~B}-47-3,21-24$ & 350 & 230 \\
$334-19-2,70-72$ & 575 & 520 \\
$334-24-3,55-58$ & 200 & 220 \\
$334-26-2,4-7$ & 575 & $>575$ \\
$335-6-5,33-35$ & 575 & 540 \\
$335-9-4,58-60$ & 575 & 490 \\
$335-10-1,22-24$ & 550 & 520 \\
$335-12-3,132-134$ & 575 & 555 \\
& & \\
\hline
\end{tabular}

${ }^{\mathrm{a}} \mathrm{T}_{1}=$ Temperature beyond which remanence is judged unstable.

${ }^{b} \mathrm{~T}_{2}=$ Temperature at which $2 / 3$ of the NRM is destroyed. 
concludes that "during step-wise thermal demagnetization new higher blocking temperature material is being formed, which, upon cooling, becomes magnetized in the same direction as the parent material.". Further work is needed to check if this explanation is valid for the present material.

\section{MICROSCOPY}

Thin wafers sawn off the same cores as the specimens used in the VRM experiment were polished and investigated by light and electron microscopy. The electron microscopy investigation is of a preliminary nature only, but it indicates that the opaque grains are not intergrown on an ultrafine scale. The optical work is summarized in Figure 2. All the grains observed were optically homogeneous, so there is no evidence of the deuteric phase-splitting so often seen in subaerial basalts. Total volume fractions, determined from 40 photomicrographs per specimen, lie between $0.5 \%$ and $2 \%$, but the opaque grains themselves vary widely in size. Most of the grains have linear dimensions of a few microns, but Sample 332B-11-1, 115-118 cm contains much larger grains, often exceeding $100 \mu \mathrm{m}$. It is noteworthy that this specimen comes from a probable doleritic intrusion, whereas the other five are basalt flows. The large opaques in this specimen are reflected in the magnetic properties; the viscosity coefficient is high (Table 1), and the NRM is very soft, being reduced to $50 \%$ in only 50 oe compared to 200 oe or more for the flows.

\section{REFERENCES}

Boetzkes, P.C. and Gough, D.I., 1976. A spinner magnetometer for susceptibility anisotropy in rocks: Canadian J. Earth Sci., v. 12, p. 1448-1464.

Irving, E., 1970 . The Mid-Atlantic Ridge at $45^{\circ}$ N. XIV. Oxidation and magnetic properties of basalt; review and discussion: Canadian J. Earth Sci,, v. 7, p. 1528-1538.

Irving, E., Robertson, W.A., and Aumento, F., 1970. The Mid-Atlantic Ridge near $45^{\circ} \mathrm{N}$. VI. Remanent intensity, susceptibility, and iron content of dredged samples: Canadian J. Earth Sci., v. 7, p. 226-238.
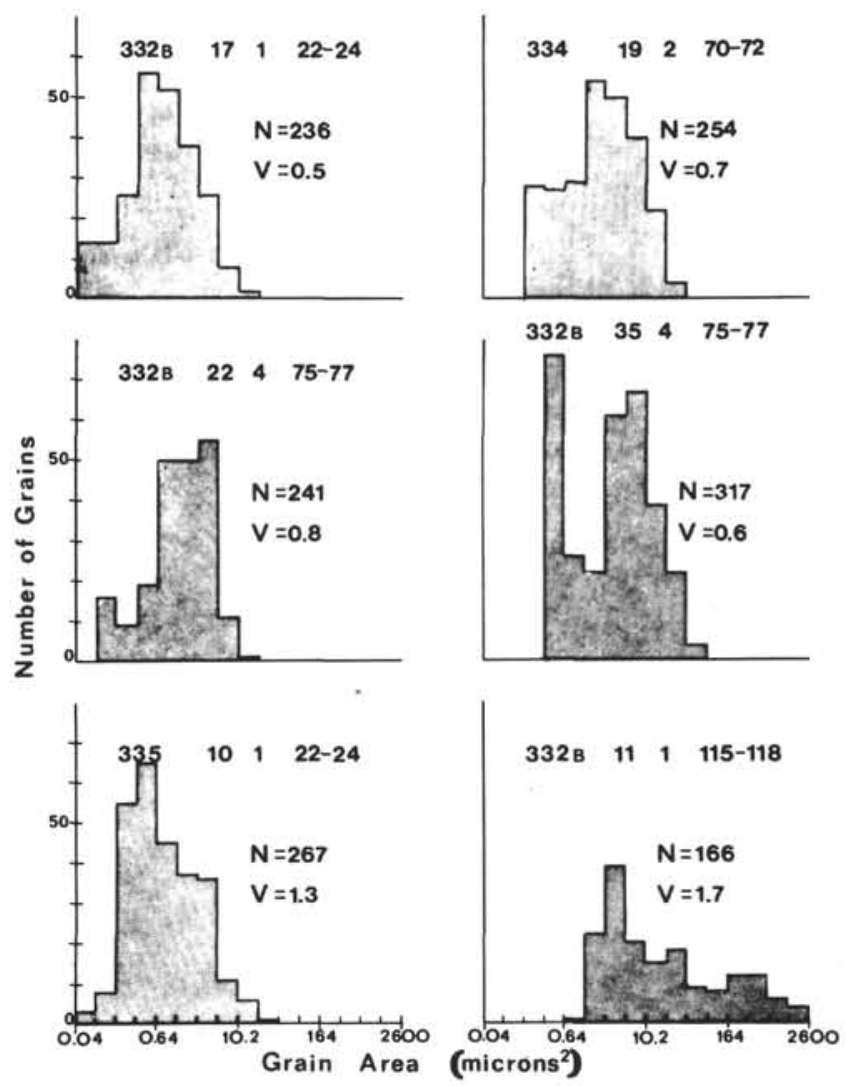

Figure 2. Size distributions of opaque grains in six specimens. $\mathrm{N}$ is the number of grains measured on each specimen and $\mathrm{V}$ is the total volume percentage represented by opaque grains. Measurements were made from photomicrographs using rectilinear grids.

McElhinny, M.W., 1973. Palaeomagnetism and plate tectonics: Cambridge (Cambridge University Press).

Shimuzu, Y., 1960. Magnetic Viscosity of Magnetite: J. Geomag. Geoelec., v. 11, p. 125-138. 